\title{
Risk Factor Assessment
}

National Cancer Institute

\section{Source}

National Cancer Institute. Risk Factor Assessment. NCI Thesaurus. Code C90498.

A systematic gathering of information regarding the variables associated with an individual's increased risk of disease or infection. 